\title{
Manejo de Paspalum dilatatum Poir. biótipo Virasoro. 1. Produção, composição química e persistência ${ }^{1}$
}

\author{
Karinne Baréa² ${ }^{2}$ Simone Meredith Scheffer-Basso ${ }^{3}$, Miguel Dall'Agnol $^{4}$, Bárbara Natália de Oliveira $^{5}$ \\ ${ }^{1}$ Parte do trabalho de dissertação de Mestrado da primeira autora. \\ 2 Bióloga, MSC. \\ ${ }^{3}$ Universidade de Passo Fundo. \\ ${ }^{4}$ Universidade Federal do Rio Grande do Sul. Bolsista CNPq. \\ ${ }^{5}$ Acadêmica do curso de Ciências Biológicas, Universidade de Passo Fundo. Bolsista PIBIC/CNPq.
}

RESUMO - Objetivou-se avaliar o efeito da altura $(10$ e $20 \mathrm{~cm}$ ) e do intervalo de cortes (30 e 45 dias) na produção de MS, na composição química e na persistência do capim-melador (Paspalum dilatatum Poir. biótipo Virasoro) em condições de campo. As plantas foram cortadas nove e seis vezes, respectivamente, nos intervalos de corte de 30 e 45 dias, no período de setembro de 2003 a junho de 2004. A produção de MS total não diferiu entre as alturas nem entre os intervalos de corte (média de 2.017 g MS/linha). Houve efeito da interação estação de MS × altura de corte: não houve diferença entre primavera e verão sob cortes a $10 \mathrm{~cm}$ (997 g/linha); na altura de corte de $20 \mathrm{~cm}$, a produção obtida no verão (938 g MS/linha) foi maior que a da primavera (761 g MS/linha), enquanto, a $10 \mathrm{~cm}$, os cortes na primavera proporcionaram maior produção (1.030 vs $761 \mathrm{~g}$ MS/linha a $20 \mathrm{~cm}$ ). No outono, a produção de MS foi muito baixa (125 g MS/linha). A produção de folhas aumentou sob cortes freqüentes (30 dias) e intensos $(10 \mathrm{~cm})$. Nos cortes feitos a intervalos de 30 dias, houve maior teor de PB (14,7\%) e menores teores de FDA (43,8\%) e FDN (67,8\%). Os cortes não evitaram o florescimento precoce, intenso e contínuo das plantas, que alocaram, em média, $27 \%$ da MS em folhas e $68 \%$ em caules+inflorescências.

Palavras-chave: capim-melador, cortes, fibra, proteína

\section{Management of Paspalum dilatatum Poir. biotype Virasoro. 1. Production, chemical composition and persistence}

\begin{abstract}
This work aimed to evaluate the effect of the cutting height $(10 \mathrm{~cm}$ and $20 \mathrm{~cm})$ and cutting interval (30 days and 45 days) in the DM production of dallisgrass (Paspalum dilatatum Poir. biótipo Virasoro) cultivated under field conditions. Plants were cut between September/2003 and June/2004, nine and six times, for the $30 \mathrm{~d}$ and $45 \mathrm{~d}$ cutting interval, respectively. The total DM yield did not differ among treatments, with an average of 2,017 g DM/row. There was a significant interaction between season and cutting height, with no difference observed between summer and spring at $10 \mathrm{~cm}$ height (997 g DM/row); at $20 \mathrm{~cm}$ cutting height, however, there was a higher yield on the summer (938 g DM/row) than in the spring (761 g DM/row); during the spring, the $10 \mathrm{~cm}$ cutting height enhanced the DM production (1,030 g DM/row) in relation to the $20 \mathrm{~cm}$ cutting height (761 g DM/row). The fall DM production was low (125 g DM/row). The leaf yield increased under frequent (30 days) and intense $(10 \mathrm{~cm})$ cutting. The highest CP concentration (14.7\%) and the lower ADF (43.8\%) and NDF (67.8\%) concentrations were obtained under the frequency of 30 days. The cutting management did not affect the early, continuous, and intense flowering of the plants, which allocated an average of $27 \%$ of DM to the leaves and $68 \%$ to the stems + inflorescences.
\end{abstract}

Key Words: cutting, dallisgrass, fiber, protein

\section{Introdução}

No bioma Campos Sulinos, que abrange o Sul do Brasil, parte da Argentina e todo o Uruguai, o gênero Paspalum apresenta o maior número de espécies forrageiras. Para a maioria das espécies do gênero, não há indicações sobre sua resposta ao manejo, fator fundamental para garantir sua persistência nas pastagens naturais e sua utilização em estudos de melhoramento com vistas à domesticação dessas espécies. A dificuldade em se trabalhar com espécies nativas consiste principalmente na obtenção de sementes, que normalmente dificulta o estabelecimento de ensaios na forma de parcelas cheias, e, portanto, sua comparação a espécies domesticadas.

Entre as espécies de Paspalum, destaca-se o capimmelador (Paspalum dilatatum Poir.), por sua ampla variedade 
de biótipos que se distinguem pela ploidia, pelo modo de reprodução, pelas características morfológicas e pela área de distribuição (Burson et al., 1991). A denominação vulgar da espécie se deve à “mela”, exsudação escura e pegajosa que ocorre nas inflorescências como conseqüência da presença do fungo Claviceps paspali e que pode afetar a saúde dos animais em pastejo. A espécie possui grande rusticidade, bom rendimento, palatabilidade e resistência ao pisoteio, características que a tornam uma das espécies mais importantes das pastagens naturais do Sul do Brasil e de países vizinhos, como Argentina e Uruguai.

Nos Estados Unidos, o capim-melador tem sido utilizado como pastagem permanente, pois inicia seu crescimento na primavera, mais cedo que as demais gramíneas perenes estivais, e responde muito bem ao pastejo, além de ter excelente valor nutritivo (Venuto et al., 2003). Na Austrália, populações oriundas do Brasil apresentaram elevadas taxas de crescimento na primavera e no início de verão, além de tolerância à geada (Shaw et al., 1965). Na Argentina, Ayala Torales et al. (2000) observaram que a freqüência de pastejos, estipulada pelo percentual de afilhos em florescimento, não afetou a produção de forragem do capim-melador. No entanto, quando as plantas foram pastejadas com freqüencia, as perdas de forragem foram maiores, em decorrência do hábito mais prostrado e de sua menor utilização.

No Brasil, o complexo de formas relacionadas a essa espécie inclui citótipos tetraplóides e sexuais, com anteras amarelas, como $P$. dilatatum subsp. flavescens e os biótipos Vacaria e Virasoro. Existe também um citótipo pentaplóide apomítico, representado pela forma típica da espécie, chamada de $P$. dilatatum Comum (anteras roxas), e citótipos hexaplóides, também apomíticos, caracterizados como biótipos Uruguaio ou Chiru, Uruguaiana e Torres (Moraes-Fernandes et al., 1968; Valls \& Pozzobon, 1987; Hickenbick et al., 1992; Machado et al., 2005). Esses biótipos foram objeto de investigação por Venuto et al. (2003), nos Estados Unidos, onde o biótipo Uruguaiana apresentou superioridade em relação ao comum, demonstrando ser uma alternativa viável para os pecuaristas do sudeste daquele país. Os autores observaram particularidades entre os biótipos quanto ao hábito de crescimento: o biótipo Torres tem hábito semi-prostrado, similar ao Comum, porém é menos tolerante ao frio; o biótipo Uruguaiana é o mais ereto em relação aos demais e mais tolerante ao frio; o biótipo Uruguaiana possui hábito de crescimento intermediário entre o Comum e o Uruguaiana.

Na região norte do Rio Grande do Sul, o biótipo Virasoro tem se destacado pela elevada freqüência em margens de rodovias, bordas de lavoura e áreas ruderais. Os primeiros estudos agronômicos com esse biótipo foram realizados por Costa et al. (2003) e Costa e Scheffer-Basso (2003) nessa região, onde foi confirmado seu comportamento tipicamente estival, florescimento precoce e intenso durante a primavera e o verão e valores de PB de até 19\% nas folhas.

Em virtude da ausência de informações sobre a resposta desse biótipo a regimes de corte, este trabalho foi realizado com o objetivo de avaliar a produção, a composição química e a persistência do capim-melador a distintas combinações de intensidade e freqüência de cortes.

\section{Material e Métodos}

O experimento foi conduzido em Passo Fundo, RS, região fisiográfica do Planalto Médio, a $28^{\circ} 15^{\prime} \mathrm{S}, 52^{\circ} 24^{\prime} \mathrm{W}$ e a $687 \mathrm{~m}$ de altitude. O clima é do tipo fundamental úmido (f), variedade específica subtropical (Cfa), com chuva bem distribuída durante o ano e temperatura média de $22^{\circ} \mathrm{C}$ (Moreno, 1961). Os dados de precipitação e as temperaturas médias mensais ocorridas no período, bem como as normais, encontram-se na Figura 1.

O ensaio consistiu de um bifatorial, no qual o capim virasoro foi avaliado quanto às respostas às combinações de alturas (10 e $20 \mathrm{~cm}$ ) e intervalos de cortes (30 e 45 dias). O delineamento foi em blocos casualizados com cinco repetições e as unidades experimentais consistiram de linhas de $4 \mathrm{~m}$ distantes $1 \mathrm{~m}$ entre si. As plantas foram estabelecidas em janeiro de 2003, por meio de mudas contendo dois afilhos, a 0,50 m de distância umas das outras, totalizando 8 plantas/linha; as seis plantas centrais formaram a área útil. As mudas foram obtidas de afilhos provenientes de plantas existentes na área experimental. O solo da área experimental, do tipo latossolo vermelho escuro distrófico, de textura argilosa, apresentava: $\mathrm{pH}=5,3 ; \mathrm{P}=13 \mathrm{mg} / \mathrm{L} ; \mathrm{K}=132 \mathrm{mg} / \mathrm{L}$ e $\mathrm{MO}=2,9 \%$.

Os cortes foram iniciados em 23 de setembro de 2003, a partir da uniformização do dossel a $15 \mathrm{~cm}$ da base das plantas, com posterior aplicação de $20 \mathrm{~kg}$ N/ha. Nessa ocasião, foi realizada avaliação em uma planta por linha, totalizando 20 plantas, para descrever a condição geral do dossel, por meio de medições de estatura, circunferência na base da touceira e número de afilhos. Nas plantas cortadas a intervalos de 30 dias, os cortes foram efetuados em 23/10/03, 20/11/03, 20/12/03 (primavera), 27/01/04, 27/02/04, 29/03/04 (verão), 27/04/04, 27/05/04 e 28/06/04 (outono), totalizando nove cortes. Naquelas cortadas a intervalos de 45 dias, os cortes foram feitos em 6/11/03, 29/12/03 (primavera), 12/02/04, 29/03/04 (verão), 13/05/04 e 28/06/04 (outono), totalizando 


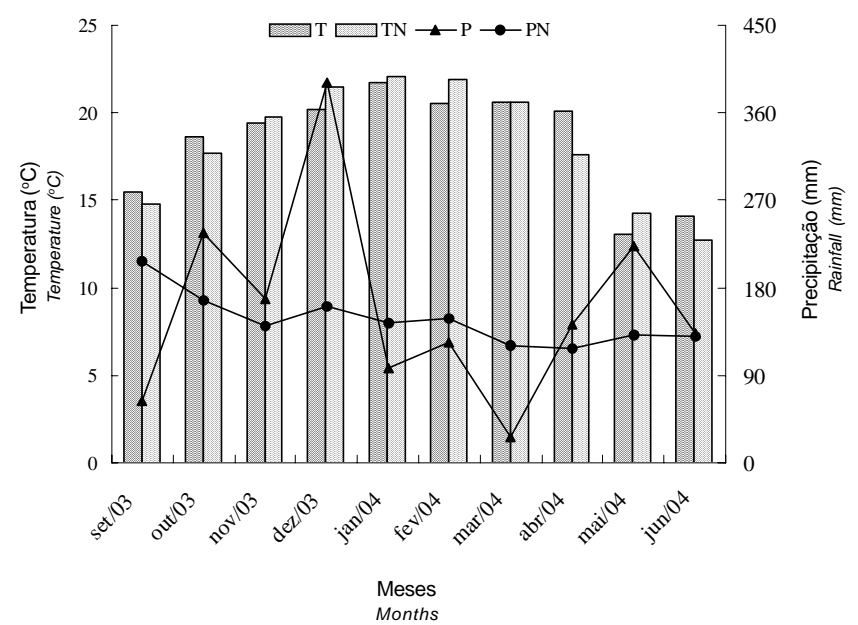

Figura 1 - Temperaturas médias e precipitação pluviométrica mensais no período de setembro de 2003 a junho de 2004 e as normais (30 anos). Passo Fundo, RS. Fonte: www.cnpt.embrapa.br.

Figure 1 - Monthly mean temperatures and rainfall between September/ 2003 and June/2004 and the normal means (30 years). Passo Fundo, RS. Source: www.cnpt.embrapa.br.

seis cortes. Após cada corte, foi aplicado nitrogênio, na forma de uréia, em um total de $160 \mathrm{~kg} \mathrm{~N} / \mathrm{ha}$, fracionados em oito doses para o intervalo de 30 dias e em cinco doses para o intervalo de 45 dias.

O local do ensaio foi mantido limpo por meio de capinas manuais. A partir de julho de 2003, foi deixado o trevobranco (Trifolium repens L.) se estabelecer nas entrelinhas, de forma espontânea, para controle de invasoras, como poaia (Richardia sp.), guanxuma (Sida rhombifolia L.), picão preto (Bidens pilosa L.) e tiririca (Cyperus sp.).

Imediatamente antes dos cortes, as plantas foram avaliadas quanto à estatura do dossel vegetativo, compreendida entre a base da planta e o topo da camada de folhas, à circunferência da base da touceira e ao número de afilhos. Em seguida, as linhas foram cortadas com tesoura de aparar gramado e o material vegetal foi pesado e amostrado para determinação do percentual de MS. Após a moagem, as amostras foram encaminhadas ao laboratório para serem analisadas quanto aos teores de PB, FDA e FDN, pelo método de espectrometria de reflectância no infravermelho proximal (NIRS). Ao início do ensaio, foi marcada (por sorteio) uma planta por parcela para separação em folhas verdes, folhas senescentes, colmos, inflorescências e material morto. Cada fração foi mantida em estufa de ventilação forçada, a $60^{\circ} \mathrm{C}$, durante 72 horas, e posteriormente for pesada. A persistência do estande foi avaliada considerando a sobrevivência e condição das plantas na linha ao final do ensaio.

Os dados foram submetidos à análise estatística, de modo que, para a produção de MS total do período avaliado, a análise da variância foi realizada em esquema bifatorial. Para as variáveis relacionadas às estações do ano, foi utilizado o esquema de parcela subdividida no tempo.

\section{Resultados e Discussão}

A produção total de MS, que totalizou as produções de primavera, verão e outono, não diferiu entre as alturas e os intervalos de corte $(\mathrm{P}>0,05)$ e variaram de 1.870 a $215 \mathrm{~g}$ MS/ linha (Figura 2). Esse comportamento sugere a adaptação da espécie aos tratamentos de corte impostos, indicando que esses cortes não foram suficientemente severos para indicar os limites de tolerância do capim-melador à desfolhação no período avaliado. Ayala Torales et al. (2000), estudando os efeitos da freqüência de pastejo na produção do capim-melador (biótipo não mencionado), também não verificaram diferença entre pastejos freqüentes (quando menos de 5\% do dossel estava com inflorescências) e menos freqüentes (quando mais de $75 \%$ dos afilhos estavam em florescimento).

Holt \& McDaniel (1963), durante dois anos, nos Estados Unidos, também observaram comportamento similar e constataram que a produção de MS do capim-melador não foi influenciada pela freqüência de cortes, porém, foi mais intensa sob cortes baixos $(7 \mathrm{~cm})$ em comparação à obtida com cortes menos intensos $(14 \mathrm{~cm})$. Neste trabalho, a máxima produção de MS foi obtida em dezembro e, dessa época até fevereiro, a produção correspondeu a $66 \%$ do total produzido (Figura 3). No intervalo de 45 dias, a maior produção ocorreu em fevereiro e correspondeu a 65\% do total. Assim, mesmo com produções similares $(\mathrm{P}>0,05)$ nas duas freqüências de corte (1.946 e $2.088 \mathrm{~g}$ MS/linha), a maior freqüencia promoveu melhor distribuição da produção na estação quente.

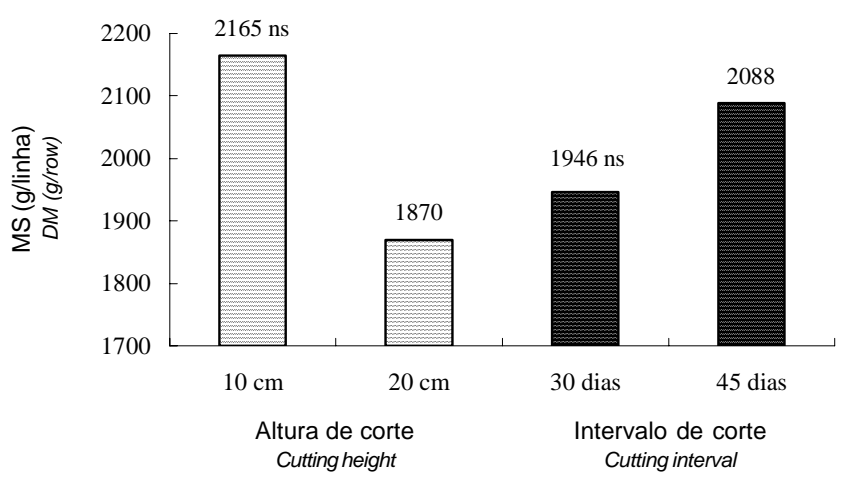

Figura 2 - Produção total de MS de Paspalum dilatatum biótipo Viraroso considerando o manejo de corte.

Figure 2 - Total DM production of Paspalum dilatatum biotype Viraroso considering the cutting management. 
A produção estacional foi afetada pela altura de corte (Tabela 1); na primavera, a produção de MS obtida com cortes a $10 \mathrm{~cm}$ de altura foi 35\% superior à encontrada com cortes a $20 \mathrm{~cm}$. Esse resultado pode ser atribuído às variações na estatura do dossel vegetativo nas duas estações (Figura 4). Na primavera, o aumento na estatura das plantas foi menor (7\%) que o observado no verão $(29,8 \%)$, provavelmente em virtude da menor intensidade de corte $(20 \mathrm{~cm})$. Conseqüentemente, a fração colhida na primavera à altura de 20 cm sofreu redução de 23,9\% em relação à encontrada com 10 cm e, portanto, a produção de MS foi menor (-26\%). No verão, em virtude do expressivo aumento na estatura do dossel em resposta aos cortes menos intensos $(20 \mathrm{~cm})$, a fração colhida foi praticamente a mesma, o que permitiu a obtenção de produções de MS similares $(\mathrm{P}>0,05)$.

As alterações em estatura observadas neste trabalho estão relacionadas à fenologia da espécie, cujo pico de florescimento no Sul do País ocorre a partir de dezembro, ocasionando hábito mais ereto nas plantas. Em condições de crescimento ininterrupto, Costa \& Scheffer-Basso (2003) estimaram a estatura do dossel vegetativo do capim-melador de no máximo $60 \mathrm{~cm}$. No entanto, nesta pesquisa, a primavera foi a primeira estação de desfolhação. Portanto, o efeito do manejo mais intenso ainda não havia se refletido nas plantas. Holt \& McDaniel (1963), em experimento com capim-melador Comum, observaram a pronta recuperação da coroa, das raízes e dos colmos basilares das plantas no início da primavera, período de maior crescimento ativo da espécie. É possível que, a longo prazo, o comportamento verificado neste trabalho possa ser diferente, em razão do efeito cumulativo de desfolhações sistemáticas. Além disso, a primavera foi uma estação com precipitações

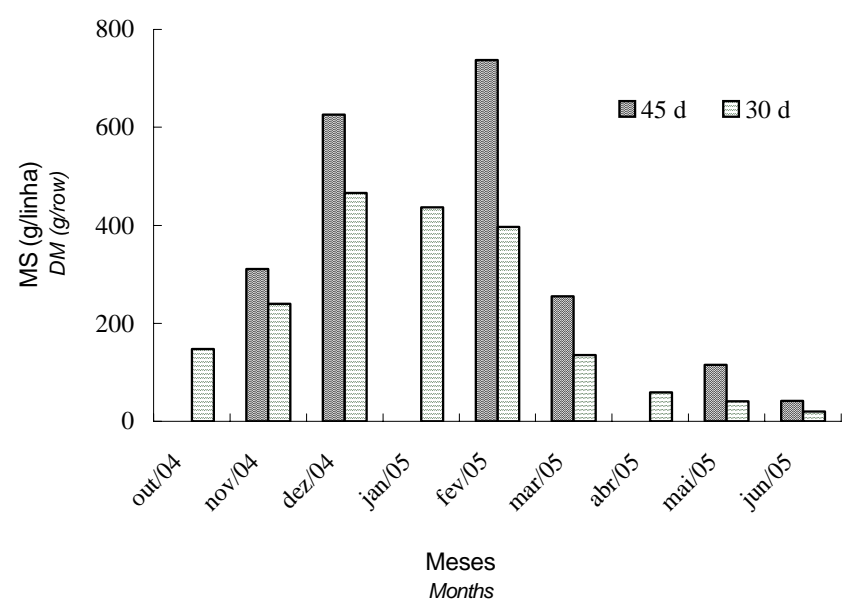

Figura 3 - Produção mensal de MS de Paspalum dilatatum biótipo Virasoro considerando o intervalo de corte.

Figure 3 - Monthly DM production of Paspalum dilatatum biotype Virasoro considering the cutting interval.
Tabela 1 - Produção estacional e alocação de MS de Paspalum dilatatum biótipo Virasoro considerando a altura de corte

Table 1 - DM seasonal production and allocation of Paspalum dilatatum biotype Viraroso considering the cutting height

\begin{tabular}{|c|c|c|}
\hline \multirow[t]{2}{*}{$\begin{array}{l}\text { Estação } \\
\text { Season }\end{array}$} & \multicolumn{2}{|c|}{$\begin{array}{l}\text { Altura de corte } \\
\text { Cutting height }\end{array}$} \\
\hline & $10 \mathrm{~cm}$ & $20 \mathrm{~cm}$ \\
\hline & \multicolumn{2}{|c|}{$\begin{array}{l}\text { MS (g/linha) } \\
\text { DM (g/row) }\end{array}$} \\
\hline Primavera (Spring) & $1.030,5 \mathrm{aA}$ & $761,3 \mathrm{bB}$ \\
\hline Verão (Summer) & 963,6aA & $938,4 \mathrm{aA}$ \\
\hline \multirow[t]{2}{*}{ Outono (Fall) } & $138,8 \mathrm{bA}$ & $124,7 \mathrm{cA}$ \\
\hline & \multicolumn{2}{|c|}{$\begin{array}{l}\text { Alocação em folhas verdes (\%) } \\
\text { Green-leaf allocation }\end{array}$} \\
\hline Primavera (Spring) & $34,0 \mathrm{bA}$ & $26,0 \mathrm{bB}$ \\
\hline Verão (Summer) & $26,9 \mathrm{cA}$ & $21,2 \mathrm{cB}$ \\
\hline \multirow[t]{2}{*}{ Outono (Fall) } & $85,1 \mathrm{aA}$ & 82,3 a A \\
\hline & \multicolumn{2}{|c|}{$\begin{array}{c}\text { Alocação em colmos + inflorescências (\%) } \\
\text { Stems }+ \text { inflorescences allocation }\end{array}$} \\
\hline Primavera (Spring) & $64,1 \mathrm{aB}$ & 72,1aA \\
\hline Verão (Summer) & $64,4 \mathrm{aA}$ & $72,4 a A$ \\
\hline Outono (Fall) & $10,1 \mathrm{cA}$ & 8,3bA \\
\hline
\end{tabular}

Médias seguidas pela mesma letra, minúsculas na coluna e maiúsculas na linha, não diferem $(P>0,05)$ pelo teste Tukey.

Means followed by the same letter, small in the column and capital in the row, do not differ $(P>0.05)$ by Tukey test.

pluviométricas acima do normal (Figura 1), o que favoreceu a rebrota, mesmo sob cortes mais intensos. Acosta et al. (1994), em estudo com o capim-melador na Argentina, também observaram excelente rebrota e resistência à desfolhação. Investigações de Deregibus \& Trlica (1990), também na Argentina, também comprovaram sua elevada tolerância a cortes intensos (2 a $3 \mathrm{~cm}$ ), desde que não freqüentes, atribuída ao estímulo ao afilhamento na base das touceiras, em virtude de respostas morfogênicas promovidas pela melhor condição de luminosidade. Segundo os autores, é possível que, sob boas condições de crescimento e em situações em que a assimilação de carbono não é muito limitada, determinadas gramíneas possam aumentar o afilhamento quando desfolhadas.

Segundo Costa \& Scheffer-Basso (2003), o capimmelador concentra o material morto no centro da touceira, em decorrência da senescência natural dos afilhos, o que pode explicar, em parte, a vigorosa rebrota deste biótipo após os cortes, que removeram parte desse material do centro das plantas, melhorando as condições de luminosidade e ativando as gemas basilares. A rebrota dessa gramínea também deve ser creditada à existência de rizomas curtos, dos quais emergem novas brotações e, com isso, aumentam paulatinamente a circunferência das plantas, substituindo os afilhos mortos. 
Estruturalmente, a forragem colhida nas estações avaliadas diferiu significativamente, especialmente se comparada à obtida nas estações primavera-verão e outono (Tabela 2). No outono, em razão da ausência do florescimento, mais de $85 \%$ da MS foi alocada em folhas verdes, enquanto, nas estações de pico de crescimento, ocorreu o inverso: na primavera e no verão, a alocação média em folhas verdes foi de $27 \%$ e em colmos + inflorescências, 68\%. Na primavera, a vantagem dos cortes mais intensos $(10 \mathrm{~cm})$ também foi evidenciada pelo aumento de 30\% na proporção de folhas, o que é desejável sob o aspecto da qualidade da forragem. Independentemente do manejo, o capim-melador alocou a maior parte da MS em afilhos reprodutivos, o que não é interessante em sistemas de produção animal, embora seja importante para a ressemeadura natural.

Esse modelo de alocação está estreitamente relacionado ao seu padrão fenológico, caracterizado pelo florescimento precoce, contínuo e intenso durante toda a estação quente. Costa et al. (2003) verificaram esse comportamento no capim-melador e sugeriram um manejo que pudesse retardar ou inibir esse processo. Bennett (1976) também recomendou o pastejo no capim-melador durante o período vegetativo para encurtar o período de florescimento. No entanto, considerando os resultados obtidos neste trabalho, os cortes periódicos e precoces não evitaram esse evento. Fato similar foi verificado por Deregibus \& Trlica (1990) em capimmelador sob condições de primavera úmida. Esses autores notaram maior florescimento nessa estação, porém, quando

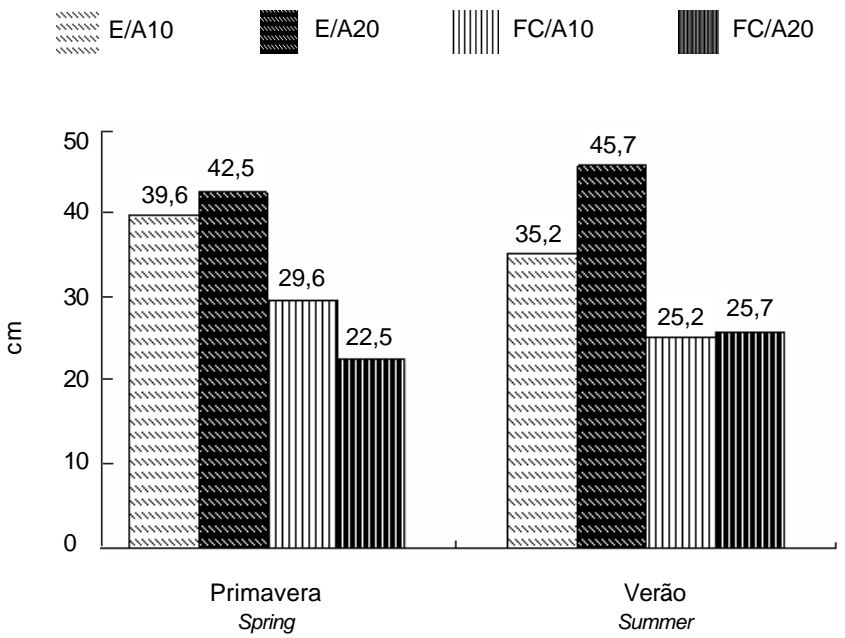

Figura 4 - Estatura (E) e fração colhida (FC) do dossel vegetativo de Paspalum dilatatum biótipo Virasoro considerando a alturas de corte $(A=10$ e $20 \mathrm{~cm})$.

Figure 4 - Canopy height (E) and harvested fraction (FC) of Paspalum dilatatum biotype Virasoro considering the cutting height $(A=10$ and $20 \mathrm{~cm})$.
Tabela 2 - Alocação estacional da MS de Paspalum dilatatum biótipo Virasoro considerando a altura de corte

Table 2 - Seasonal DM allocation of Paspalum dilatatum biotype Viraroso considering the cutting height

\begin{tabular}{|c|c|c|}
\hline \multirow[t]{2}{*}{$\begin{array}{l}\text { Estação } \\
\text { Season }\end{array}$} & \multicolumn{2}{|c|}{$\begin{array}{l}\text { Altura de corte } \\
\text { Cutting height }\end{array}$} \\
\hline & $10 \mathrm{~cm}$ & $20 \mathrm{~cm}$ \\
\hline \multirow{5}{*}{$\begin{array}{l}\text { Primavera (Spring) } \\
\text { Verão (Summer) } \\
\text { Outono (Fall) }\end{array}$} & \multicolumn{2}{|c|}{$\begin{array}{c}\text { Folhas verdes (\%) } \\
\text { Green leaves }\end{array}$} \\
\hline & $34,0 \mathrm{bA}$ & $26,0 \mathrm{bB}$ \\
\hline & 26,9 cA & $21,2 \mathrm{cB}$ \\
\hline & $85,1 \mathrm{aA}$ & 82,3 aA \\
\hline & \multicolumn{2}{|c|}{$\begin{array}{c}\text { Colmos+inflorescências (\%) } \\
\text { Stems+inflorescences }\end{array}$} \\
\hline Primavera (Spring) & $64,1 \mathrm{aB}$ & $72,1 \mathrm{aA}$ \\
\hline Verão (Summer) & $64,4 \mathrm{aA}$ & $72,4 \mathrm{aA}$ \\
\hline Outono (Fall) & $10,1 \mathrm{cA}$ & 8,3bA \\
\hline
\end{tabular}

As médias seguidas de mesma letra, minúscula na coluna e maiúscula na linha, não diferem $(P>0,05)$ pelo teste Tukey.

Means followed by the same letter, small in the column and capital in the row, do not differ $(P>0.05)$ by Tukey test.

as condições foram menos favoráveis, observaram inibição desse processo, evidenciando uma estratégia oportunista quanto ao esforço reprodutivo.

As alterações na alocação de MS se refletiram também na composição química da forragem colhida (Tabela 3), especialmente no conteúdo de PB, cujos teores apresentaram a mesma tendência verificada para a proporção de folhas na MS (Tabela 1).

A maior concentração de PB foi obtida no outono, estação em que a fração colhida foi formada basicamente por folhas. No entanto, a composição química nas estações variou de acordo com a freqüência de cortes; em geral, sob cortes mais freqüentes, obteve-se forragem com melhor composição química, evidenciada pelo maior teor de PB e pelo menor conteúdo de FDA e FDN.

Os teores de PB obtidos neste estudo indicam o bom valor nutritivo do capim-melador em comparação a outras espécies tropicais. Gerdes et al. (2000) relataram valores de PB de 15,3 e 7,5\% nas lâminas foliares e hastes de Panicum maximum Jacq. cv. Tanzânia-1. Oliveira et al. (2000), avaliando o cultivar tifton 85 (Cynodon sp.), obtiveram valores de 15,6 a 4,5\% de $\mathrm{PB}$ dos 14 aos 70 dias de idade para a planta inteira, enquanto o teor de PB na lâmina foliar atingiu valor mínimo de 8,24\% aos 70 dias de rebrota. Com capim-melador Comum, Ayala Torales et al. (2000) estimaram teores de $11 \%$ de PB, enquanto Costa et al. (2003) obtiveram valores máximos de 19 (lâmina foliar), 10,4 (bainha foliar) e 9,7\% (colmo) no capim-melador.

Os resultados de FDN foram similares aos obtidos por Venuto et al. (2003), que encontraram teores médios de 70\% 
Tabela 3 - Teores de PB, FDA e FDN de Paspalum dilatatum biótipo Virasoro considerando o intervalo de corte

Table 3 - $\quad C P, A D F$ and NDF concentrations of Paspalum dilatatum biotype Virasoro considering the cutting interval

\begin{tabular}{|c|c|c|}
\hline \multirow[t]{2}{*}{$\begin{array}{l}\text { Estação } \\
\text { Season }\end{array}$} & \multicolumn{2}{|c|}{$\begin{array}{l}\text { Intervalo de corte } \\
\text { Cutting interval }\end{array}$} \\
\hline & $\begin{array}{l}30 \text { dias } \\
30 \text { days }\end{array}$ & $\begin{array}{l}45 \text { dias } \\
45 \text { days }\end{array}$ \\
\hline & \multicolumn{2}{|c|}{ PB (\%) (CP) } \\
\hline Primavera (Spring) & $14,2 \mathrm{bA}$ & $11,6 \mathrm{bB}$ \\
\hline Verão (Summer) & $11,3 \mathrm{cA}$ & $10,7 \mathrm{cB}$ \\
\hline \multirow[t]{2}{*}{ Outono (Fall) } & $18,6 \mathrm{aA}$ & $16,9 a \mathrm{~B}$ \\
\hline & \multicolumn{2}{|c|}{ FDN (\%) (NDF) } \\
\hline Primavera (Spring) & $67,3 \mathrm{bB}$ & $71,8 \mathrm{aA}$ \\
\hline Verão (Summer) & $69,1 \mathrm{aA}$ & $70,3 \mathrm{bA}$ \\
\hline \multirow[t]{2}{*}{ Outono (Fall) } & $66,4 \mathrm{bB}$ & $68,5 \mathrm{cA}$ \\
\hline & \multicolumn{2}{|c|}{ FDA $(\%)(A D F)$} \\
\hline Primavera (Spring) & $44,9 b B$ & $46,8 \mathrm{bA}$ \\
\hline Verão (Summer) & $45,8 \mathrm{aA}$ & $46,1 \mathrm{bA}$ \\
\hline Outono (Fall) & 40,6 сB & $42,4 \mathrm{aA}$ \\
\hline
\end{tabular}

Médias seguidas de mesma letra, minúscula na coluna e maiúscula na linha, não diferem $(P>0,05)$ pelo teste Tukey.

Means followed by the same letter, small in the column and capital in the row, do not differ $(P>0.05)$ by Tukey test

de FDN para os biótipos Uruguaiana e Comum, no Texas. Os teores de FDA foram semelhantes aos verificados por Acosta et al. (1996), de 38,8\% na primavera, 39,7\% no verão e 35,8\% no outono com o biótipo Comum. Costa et al. (2003) quantificaram, para o capim-melador, teores médios de FDN de 62,3\% na lâmina foliar e 63,4\% nos colmos e valores de FDA de 36,2\% nas lâminas foliares e 40,3\% nos colmos.

O efeito do intervalo de corte foi especialmente observado na proporção de folhas existentes na MS da primavera e do outono (Tabela 4). No verão, não houve alteração significativa dessa fração. Na primavera e no verão, cortes menos freqüentes aumentaram significativamente a fração colmo, ao passo que, considerando apenas as inflorescências, houve redução proporcional no maior intervalo de cortes, provavelmente em virtude do maior alongamento dos afilhos reprodutivos e, conseqüentemente, da maior proporção de colmos.

As plantas não apresentaram sintomas que evidenciassem a presença do fungo Claviceps paspali, o que é altamente desejável sob os aspectos da nutrição animal e da produção de sementes. Na Argentina, Schrauf et al. (2003), ao inocularem plantas do capim-melador com conídios de $C$. paspali, verificaram total susceptibilidade ao fungo, ao contrário do normalmente observado por Costa \& SchefferBasso (2003), no Rio Grande do Sul, em experimentos com esse biótipo.
Tabela 4 - Contribuição relativa de folhas verdes, colmos e inflorescências em Paspalum dilatatum biótipo Virasoro considerando o intervalo de corte

Table 4 - Relative contribution of green leaves, stems and inflorescences in Paspalum dilatatum biotype Virasoro considering the cutting interval

\begin{tabular}{|c|c|c|}
\hline \multirow[t]{2}{*}{$\begin{array}{l}\text { Estação } \\
\text { Season }\end{array}$} & \multicolumn{2}{|c|}{$\begin{array}{l}\text { Intervalo de corte } \\
\text { Cutting interval }\end{array}$} \\
\hline & $\begin{array}{l}30 \text { dias } \\
30 \text { days }\end{array}$ & $\begin{array}{l}45 \text { dias } \\
45 \text { days }\end{array}$ \\
\hline & \multicolumn{2}{|c|}{$\begin{array}{c}\text { Folhas verdes (\%) } \\
\text { Green leaves }\end{array}$} \\
\hline Primavera (Spring) & $32,0 \mathrm{bA}$ & $28,0 \mathrm{bB}$ \\
\hline Verão (Summer) & $24,8 \mathrm{cA}$ & $23,2 \mathrm{cA}$ \\
\hline \multirow[t]{2}{*}{ Outono (Fall) } & $87,9 \mathrm{aA}$ & $79,4 \mathrm{aB}$ \\
\hline & \multicolumn{2}{|c|}{$\begin{array}{l}\text { Colmos }(\%) \\
\text { Stems }\end{array}$} \\
\hline Primavera (Spring) & $30,9 \mathrm{aB}$ & $43,9 \mathrm{aA}$ \\
\hline Verão (Summer) & $26,0 \mathrm{bB}$ & $31,0 \mathrm{bA}$ \\
\hline \multirow[t]{2}{*}{ Outono (Fall) } & $1,6 \mathrm{cA}$ & 4,1cA \\
\hline & \multicolumn{2}{|c|}{$\begin{array}{c}\text { Inflorescências (\%) } \\
\text { Inflorescences }\end{array}$} \\
\hline Primavera (Spring) & $35,7 \mathrm{bA}$ & $25,8 b B$ \\
\hline Verão (Summer) & $46,1 \mathrm{aA}$ & $36,6 a B$ \\
\hline Outono (Fall) & 6,3cA & $6,5 \mathrm{cA}$ \\
\hline
\end{tabular}

Médias seguidas de mesma letra, minúscula na coluna e maiúscula na linha, não diferem $(P>0,05)$ pelo teste Tukey.

Means followed by the same letter, small in the column and capital in the row, do not differ $(P>0.05)$ by Tukey test.

Ao final do período de cortes, as plantas apresentaram 100\% de sobrevivência, comprovando sua tolerância às combinações de intensidade e freqüência de cortes. Para melhor descrever o efeito do manejo na condição das plantas, foi realizada uma comparação entre as plantas ao primeiro e ao último corte, ou seja, quando as plantas estavam com 18 meses de idade (Tabela 5).

A estatura reduziu em 42,4\% entre o primeiro e o último corte nas plantas cortadas a $10 \mathrm{~cm}$ e $21,9 \%$ naquelas cortadas a $20 \mathrm{~cm}$, comprovando, portanto, que, apesar de a produção total do período não ter alterado entre os manejos, a médio e longo prazos, pode-se esperar alguma mudança nesse aspecto. A menor estatura, observada em junho, pode ser atribuída às condições térmicas desfavoráveis ao crescimento do capim-melador, que é estival. A tendência verificada para circunferência e área basal das touceiras foi inversa, pois essas medidas aumentaram com o crescimento das plantas e com o constante afilhamento em nível basilar. Esse aumento, porém, foi menor nas plantas cortadas a $10 \mathrm{~cm}(69,5 \%)$ em relação àquelas cortadas a $20 \mathrm{~cm}$ (85\%), demonstrando vantagem dos cortes menos intensos sobre esse parâmetro de crescimento. A circun- 
Tabela 5 - Caracteres morfológicos de Paspalum dilatatum biótipo Virasoro no primeiro e último cortes considerando o manejo de corte

Table 5 - Morphological characters of Paspalum dilatatum biotype Virasoro on the first and last cuts considering the cutting management

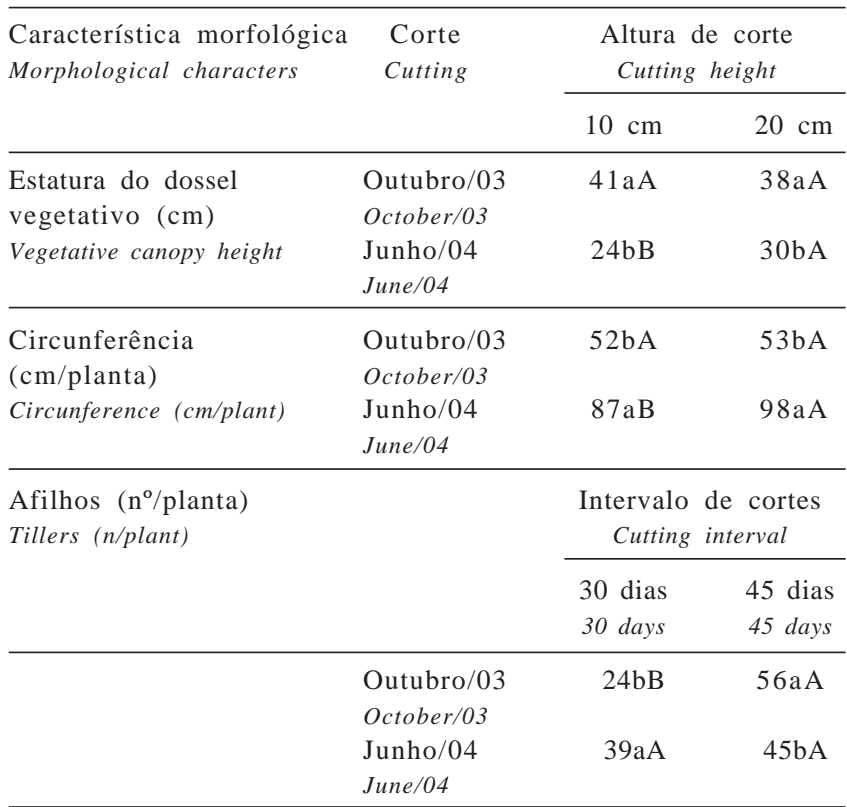

Médias seguidas pela mesma letra, minúscula na coluna e maiúscula na linha, não diferem $(P>0,05)$ pelo teste Tukey.

Means followed by the same letter, small in the column and capital in the row, do not differ $(P>0.05)$ by Tukey test.

ferência das plantas cortadas a 20 cm na ocasião do último corte foi $12,2 \%$ superior à observada nas plantas cortadas a $10 \mathrm{~cm}$.

A perenidade e recuperação da planta após o corte ou pastejo depende da contínua formação de novos afilhos (Briske, 1991). Segundo Mathew et al. (1995), o afilhamento é geralmente um indicador de vigor e persistência de plantas forrageiras ou uma variável-resposta a práticas de manejo. Neste estudo, comparando o número de afilhos entre o início e o final do período de utilização, verificou-se sua dependência do intervalo de cortes (Tabela 4). Nos cortes realizados em intervalos de 30 dias, o número de afilhos foi de $62 \%$ entre o primeiro e o último cortes, enquanto, nos intervalos de 45 dias, houve redução de 24,4\%. Essa resposta pode ser atribuída à diferença inicial no primeiro corte, uma vez que, entre os dois intervalos, houve diferença de 15 dias, período no qual as plantas apresentaram elevado ritmo de crescimento, com taxa média diária de 2 afilhos/dia. Ao final do período, no entanto, apesar dos $13,8 \%$ a mais de afilhos nos cortes a intervalos de 45 dias, a diferença não foi significativa, comprovando, novamente, a versatilidade do biótipo aos níveis de desfolhação impostos, bem como sua recuperação.

\section{Conclusões}

A composição química e a distribuição da produção de forragem do capim-melador são alteradas pela freqüência de desfolhação. Cortes em intervalos de 30 dias, a $10 \mathrm{~cm}$ da base das plantas, possibilitam colheitas mais estáveis na estação de crescimento, com maior conteúdo de PB e menores teores de FDA e FDN, em decorrência da maior alocação de MS em folhas verdes.

\section{Agradecimento}

Ao Dr. Roberto Serena Fontaneli, pelo auxílio nas análises químicas, e à Profa. Dileta Cecchetti, pelo apoio na análise estatística.

\section{Literatura Citada}

ACOSTA, G.; DEREGIBUS, V.A.; ZUCCHINI, F. Inclusión de pasto Miel ( $P$. dilatatum Poir.) en pasturas. 1. Efecto sobre la producción forrajera. Revista Argentina de Produção Animal, v.14, p.175-185, 1994.

ACOSTA, G.; DEREGIBUS, V.A.; HAMMAR ALDATZ, R. Inclusión de pasto Miel ( $P$. dilatatum Poir.) en pasturas. 2. Efecto sobre el valor nutritivo. Revista Argentina de Produção Animal, v.16, n.2, p.157-167, 1996.

AYALA TORALES, A.; ACOSTA, G.L.; DEREGIBUS, V.A. et al. Effects of grazing frequency on the production, nutritive value, herbage utilization, and structure of a Paspalum dilatatum sward. New Zealand Journal of Agricultural Research, v.43, p.467-472, 2000.

BENNETT, H.W. Pasto Dallis, pasto Bahía y pasto Vasey. In: HUGHES, H.D.; HEATH, M.E.; METCALFE, D.S. (Eds.). Forrajes. México: Compañia Editorial Continental, 1976. p.315-319.

BRISKE, D.D. Developmental morphology and physiology of grasses. In: HUTSCHMIDE, R.K.; STUTHRED, J.W. (Eds.) Grazing management an ecological perspective. Portland: Timber Press, 1991. p.85-108.

BURSON, B.L.; VOIGT, P.W.; EVERS, G.W. Cytology, reproductive behavior, and forage potential of hexaploid dallisgrass biotypes. Crop Science, v.31, p.636-641, 1991.

COSTA, D.I.; SCHEFFER-BASSO, S.M. Caracterização morfofisiológica e agronômica de Paspalum dilatatum Biótipo Virasoro e Festuca arundinacea Schreb. 1. Desenvolvimento morfológico. Revista Brasileira de Zootecnia, v.32, p.10541060, 2003.

COSTA, D.I.; SCHEFFER-BASSO, S.M.; FAVERO, D. et al. Caracterização morfofisiológica e agronômica de Paspalum dilatatum Biotipo Virasoro e Festuca arundinacea Schreb. 2. Disponibilidade de forragem e valor nutritivo. Revista Brasileira de Zootecnia, v.32, p.1061-1067, 2003.

DEREGIBUS, V.A.; TRLICA, M.J. Influence os defoliation upon tiller structure and demongraphy in two warm-season grasses. Acta Ecologica, v.11, p.693-699, 1990.

GERDES, L.; WERNER, J.C.; COLOZZA, M.T. et al. Avaliação de características das gramíneas forrageiras Marandu, Setária e Tanzânia nas estações do ano. Revista Brasileira de Zootecnia, v.29, p.955-963, 2000.

HICKENBICK, M.C.M.; FLORES, A.I.; CAVALLI-MOLINA, S. et al. Mode of reproduction and seed production in Paspalum dilatatum Poir. Virasoro biotype - Dilatata group (Gramineae) Revista Brasileira de Genética, v.15, p.85-102, 1992. 
HOLT, E.C.; McDANIEL, J.C. Influence of clipping on yield, regrowth, and root development of dallisgrass, Paspalum dilatatum Poir., and kleingrass, Panicum coloratum L. Agronomy Journal, v.55, p.561-564, 1963.

MACHADO, A.C.C.; VALLS, J.F.M.; PEÑALOZA, A.P.S. et al. Novos biótipos pentaplóides do grupo Dilatata de Paspalum L. (Gramineae) no Sul do Brasil. Ciência Rural, v.35, p.56-61, 2005.

MATHEW, C.; LEMAIRE, G.; HAMILTON, N.R.S. et al. A modified self-thinning equation to describe size density relationship for defoliated swards. Annals of Botany, v.76, p.579-587, 1995.

MORAES-FERNANDES, M.I.B.; BARRETIM I.L.; SALZANO, F.M. Cytogenetic, ecologic and morphologic studies in Brazilian forms os Paspalum dilatatum. Canadian Journal of Genetics and Cytology, v.10, p.131-138, 1968.

MORENO, J.A. Clima do Rio Grande do Sul. Porto Alegre: Secretaria de Agricultura, 1961. 41p.

OLIVEIRA, M.A.; PEREIRA, O.G.; GARCIA, R. et al. Rendimento e valor nutritivo do capim-tifton 85 (Cynodon spp.) em diferentes idades de rebrota. Revista Brasileira de Zootecnia, v.29, p.1949-1960, 2000.
SHAW, N.H.; ELICH, T.W.; HAYDOCK, K.P. et al. A comparison of seventeen introductions of Paspalum species and naturalized $P$. dilatatum under cutting at Samford southeastern Queesland. Australian Journal of Experimental Agriculture and Animal Husbandry, v.5, p.423-432, 1965.

SCHRAUF, G.E.; BLANCO, M.A.; CORNAGLIA, P.S. et al. Ergot resistence in plants of Paspalum dilatatum incorporated by hibridisation with Paspalum urvillei. Tropical Grasslands, v.37, p.182-186, 2003.

VALLS, J.F.M.; POZZOBON, M.T. Variação apresentada pelos principais grupos taxonômicos de Paspalum com interesse forrageiro no Brasil. In: ENCONTRO INTERNACIONAL SOBRE MELHORAMENTO GENÉTICO DE PASPALUM, 1987, Nova Odessa. Anais... Nova Odessa: SAPF/IZ, 1987. p.15-21.

VENUTO, B.C.; BURSON, B.L.; HUSSEY, D.D. et al. Forage yield, nutritive value and grazing tolerance of dallisgrass biotypes. Crop Science, v.43, p.295-301, 2003. 